\title{
Variation of the North Atlantic subtropical high western ridge and its implication to Southeastern US summer precipitation
}

\author{
Laifang Li • Wenhong Li • Yochanan Kushnir
}

Received: 17 May 2011 / Accepted: 2 October 2011

(C) Springer-Verlag 2011

\begin{abstract}
Variations of the North Atlantic subtropical high (NASH) western ridge and their implication to the Southeastern United States (SE US) summer precipitation were analyzed for the years 1948-2007. The results show that the movement of the NASH western ridge regulates both moisture transport and vertical motion over the SE US, especially in the last three decades, during which the ridge moved westward towards the American continent. When the NASH western ridge is located southwest (SW) of its mean climate position, excessive summer precipitation is observed due to an enhanced moisture transport. In contrast, when the western ridge is located in the northwest (NW), a precipitation deficit prevails as downward motion dominates the region. Composite analysis indicates that SW ridging results mainly from the NASH center's intensification; whereas NW ridging is likely caused by stationary wave propagation from the eastern Pacific/US western coast. In recent decades, both the SW and NW ridge positions have been observed to increase in frequency. Our results suggest that the increase in the SW ridging consistently follows the NASH's intensification associated with anthropogenic forcing as projected by coupled climate models. However, the increased frequency of NW ridging tends to follow the positive Pacific decadal oscillation (PDO) index. Thus, the enhanced variability in the SE US summer precipitation in recent decades might be
\end{abstract}

L. Li · W. Li $(\bowtie)$

Earth and Ocean Sciences, Nicholas School of the Environment, Duke University, 321C Old Chem. Bldg., P. O. Box 90227,

Durham, NC 27708, USA

e-mail: wenhong.li@duke.edu

Y. Kushnir

Lamont-Doherty Earth Observatory, Columbia University Earth Institute, Palisades, NY, USA a combined result of anthropogenic forcing and internal variability of the climate system. Results suggest that, as anthropogenic forcing continues to increase, the SE US will experience more frequent wet summers and an increase in the frequency of dry summers during positive PDO phases.

Keywords North Atlantic subtropical high . Western ridge - SE US summer precipitation . Global warming $\cdot$ PDO $\cdot$ Stationary wave activity

\section{Introduction}

In recent decades, interannual variability of summer precipitation over the Southeastern United States (SE US) significantly increased (Wang et al. 2010). Summer precipitation, especially extreme events, has a significant impact on regional hydrology, agriculture and economics. For example, the 2009 floods damaged thousands of homes and caused billions of dollars in agricultural damage (Gotvald and McCallum 2010). The lasting droughts of 2002 and 2007 caused increased stress on water resources over the SE US, especially when coming on the background of population increase and the demands of a rapidly developing economy (Manuel 2008). Understanding causes of the enhanced interannual summer precipitation variability over the SE US is of scientific, political, and economic value.

Previous studies indicate that the SE US summer precipitation is controlled by many factors including but not limited to synoptic and large-scale atmospheric circulation (Katz et al. 2003; Diem 2006; Knight and Davis 2009; Seager et al. 2009; Chan and Misra 2010; Li et al. 2011) and sea surface temperature anomaly (SSTA) (Curtis 2008; 
Mo and Schemm 2008; Wang et al. 2010). Seager et al. (2009) suggested that warm season precipitation over the SE US is mainly caused by the internal variability of the atmosphere. In contrast, other studies (e.g., Mo and Schemm 2008; Wang et al. 2010) suggested that remote forcing by SSTAs plays a potential role in the nature of the SE US summer precipitation. For example, the El Niño Southern oscillation (ENSO) tends to impact the regional amount of precipitation (Mo and Schemm 2008). During La Niña (El Niño) years, the SE US usually has a relatively dry (wet) winter but wet (dry) summer, respectively (Mo and Schemm 2008). In addition, North Atlantic SSTAs are seen to play a more important role than ENSO at both interannual (Wang et al. 2010) and decadal scales (Hu et al. 2011). Furthermore, Curtis (2008) found that the Atlantic multidecadal oscillation (AMO) potentially influences SE US summer precipitation by affecting hurricane activities.

Among all of these factors, the North Atlantic subtropical high (NASH) has been identified as one of the most important circulation factors affecting the SE region hydroclimate (Henderson and Vega 1996; Katz et al. 2003; $\mathrm{Li}$ et al. 2011). NASH is a semi-permanent high-pressure system over the North Atlantic Ocean in the lower troposphere. During summer, it intensifies with its center located near Bermuda (Seager et al. 2003; Nigam and Chan 2009). Its western ridge, extending into the SE US, supplies warm and humid air from the tropical oceans to feed large scale summer precipitation over the SE US (Stahle and Cleaveland 1992; Davis et al. 1997; Diem 2006; Gamble et al. 2008). Figure 1 shows June-July-August (JJA) mean precipitation, moisture flux, and the $500 \mathrm{hPa}$ vertical velocity associated with the NASH. Strong precipitation and vertical motion over the SE US are mainly located along the western flank of the NASH, especially along the 1,560-gpm isoline.

Previous studies suggested that the NASH western ridge tends to move westward during dry summers relative to wet summers (Diem 2006). In addition, Li et al. (2011) found that the meridional movement of the NASH western ridge is more closely correlated with the SE US summer precipitation. This has been especially the case during the last three decades when the NASH's western ridge extended closer to the US continent. However, the exact relationship between the NASH western ridge location (in longitude and latitude) and motion and precipitation variability in the SE US have not yet been systematically investigated.

In this study, we analyze the variation of the NASH western ridge relative to its climatological location and its relationship to SE US precipitation during the years 1948-2007. Our study aims to answer the following questions: what is the relationship between SE US summer precipitation and displacement of the NASH western

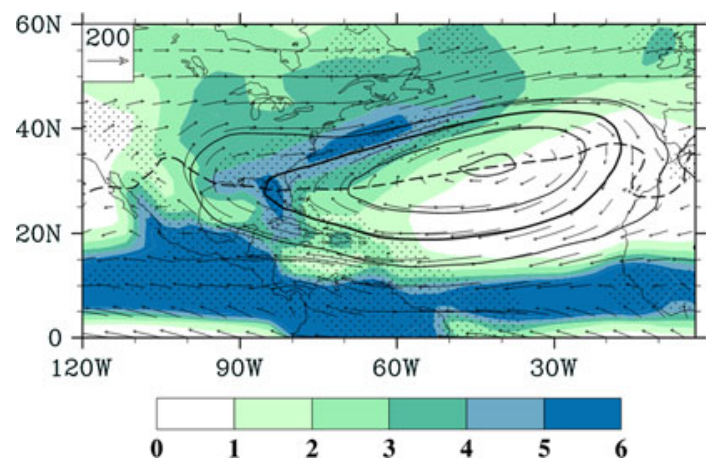

Fig. 1 JJA mean precipitation rate (shaded, unit: $\mathrm{mm} \mathrm{day}^{-1}$ ), $850 \mathrm{hPa}$ geopotential height (solid contour, unit: gpm), $850 \mathrm{hPa}$ subtropical high ridge line (dashed line) and moisture flux (vector, unit: $\mathrm{kg} \mathrm{m} \mathrm{s}^{-1}$ ). The contour interval of $850 \mathrm{hPa}$ geopotential height is 20 -gpm, and the bold curve is 1,560-gpm isoline. The area with $500 \mathrm{hPa}$ vertical velocity less than $-0.01 \mathrm{~Pa} \mathrm{~s}^{-1}$ is stippled

ridge? How could the movement of the NASH western ridge impact SE US summer precipitation, including modulation of vertical motion and moisture transport, as suggested by previous studies (Stahle and Cleaveland 1992; Davis et al. 1997; Diem 2006; Gamble et al. 2008; Li et al. 2011)? Furthermore, what are the physical mechanisms governing the variation of the NASH western ridge and its contribution to the enhanced summer precipitation variability seen in recent decades? Answers provided by the current study aids in our understanding of current and future variations of the SE US summer precipitation.

Data and methods are presented in the following section. Relationships between the SE US precipitation and the NASH western ridge, atmospheric circulation pattern associated with the different ridge positions are described in Sect. 3. Physical interpretations for two important ridge types are also listed in this section. Discussions and conclusions follow.

\section{Data and methods}

Following our previous studies (Wang et al. 2010; Li et al. 2011), relevant atmospheric circulation features are here analyzed by using the National Center of Environment Prediction/National Center of Atmospheric Research (NCEP/NCAR) reanalysis (Kalnay et al. 1996) ${ }^{1}$ during the

\footnotetext{
1 The NCEP/NCAR reanalysis used in the study is due to following reasons. First, the relatively longer period data availability of the NCEP/NCAR reanalysis matches the precipitation data (1948-2007); second, NCEP/NCAR reanalysis reasonably represents the locations of the NASH center and its western ridge comparing with surface observational data (ICOADS); third, the NCEP/NCAR reanalysis does not show discrepancy from other reanalysis data such as the ERA-40 (1958-2002), JRA (1979-2007) for the NASH's center's intensity and the western ridge.
} 
years 1948-2007. Atmospheric variables such as geopotential height, zonal wind, meridional wind and vertical velocity (omega) are averaged over boreal summer, JJA.

The $850 \mathrm{hPa}$ geopotential height instead of sea level pressure has been chosen in this study to avoid complications due to possible topographic effects on the western edge of the NASH. The ridge-line of the subtropical highs is where winds with an easterly component reverse to winds with a westerly component, or mathematically it fulfills that $u=0$ and $\frac{\partial u}{\partial y}>0$, where $u$ is the zonal wind component (Liu and $\mathrm{Wu}$ 2004). Following our previous study (Li et al. 2011), the 1,560-gpm isoline ${ }^{2}$ is chosen to represent the boundary of the NASH. The western ridge is defined as the point of intersection between the 1,560-gpm isoline and the defined ridge line ( $\mathrm{Li}$ et al. 2011). The intensity of the NASH is defined as the maximum geopotential height at $850 \mathrm{hPa}$ in its climatological center $\left(20^{\circ}-\right.$ $45^{\circ} \mathrm{N} ; 80^{\circ}-10^{\circ} \mathrm{W}$ ) (Davis et al. 1997; Liu and $\mathrm{Wu} 2004$ ).

Precipitation data were obtained from the National Oceanic and Atmospheric Administration (NOAA) Climate Prediction Center (CPC) US. Unified Precipitation dataset (Higgins et al. 2000) during 1948-1998 and from the real-time US. Daily Precipitation Analysis for 1999-2007 (Wang et al. 2010).

In order to analyze the relationship between zonal and meridional movement of the NASH western ridge and summer precipitation over the SE US, we categorized ridge locations according to their relative position to the climatological mean NASH western ridge $\left(86^{\circ} \mathrm{W}, 27^{\circ} \mathrm{N}\right)$ during 1948-2007, dividing its area of influence into four quadrants. During the 60-year analysis period, summers with the NASH western ridge in the first, second, third, and forth quadrant were identified as Northeast (NE), Northwest (NW), Southwest (SW), Southeast (SE) years, respectively. Composite analysis of precipitation was then applied to determine the precipitation features corresponding to different positions of the NASH western ridges. To identify typical circulation conditions associated with the different location of the NASH western ridge, atmospheric circulation anomalies at upper $(200 \mathrm{hPa})$ and lower $(850 \mathrm{hPa})$ levels were also determined using composite analysis.

In order to look for the physical mechanism affecting the variability and their source, SST and atmospheric stationary wave activity flux (also known as the "Plumb flux") were examined. Links to SST forcing were studied using the NOAA Extended Reconstructed SST [ERSST Version 3, (Smith et al. 2008)]. Plumb flux, the extended

\footnotetext{
2 As convention, the $850 \mathrm{hPa}$ geopotential height is usually plotted at 60-m intervals with the reference level $1,500 \mathrm{~m}$. For the North Atlantic subtropical high, the 1,500-gpm line is far into the continent while 1,620-gpm isoline is still over the North Atlantic; The 1,560gpm line is also closely related to the distribution of precipitation and vertical motion over the eastern coast of US (Fig. 1).
}

form of the Eliassen-Palm (E-P) Flux (Plumb 1985), has previously been applied to diagnose the source regions and propagation path of stationary waves (Black 1997), atmospheric teleconnection (Franzke et al. 2001; Honda et al. 2005), and the impact of external forcing on US climate (Chen and Newman 1998; Barlow et al. 2001). The horizontal component of Plumb flux is expressed as follows:

$$
\begin{aligned}
& F_{\lambda}=\frac{p}{2 a^{2} \cos \phi}\left[\left(\frac{\partial \psi^{\prime}}{\partial \lambda}\right)^{2}-\psi^{\prime} \frac{\partial^{2} \psi^{\prime}}{\partial \lambda^{2}}\right] \\
& F_{\phi}=-\frac{p}{2 a^{2}}\left(\frac{\partial \psi^{\prime}}{\partial \lambda} \frac{\partial \psi^{\prime}}{\partial \phi}-\psi^{\prime} \frac{\partial^{2} \psi^{\prime}}{\partial \lambda \partial \phi}\right)
\end{aligned}
$$

where $p$ is the pressure level, $a$ is the Earth's radius, $\lambda$ and $\phi$ are longitude and latitude, respectively, and $\psi^{\prime}$ represents the deviation of stream function from its zonal mean value. For steady flows over reasonably long periods, such as the seasonal mean, Plumb flux is parallel to the group velocity of the stationary waves and its divergence (convergence) is associated with their source (sink) (Plumb 1985).

The Monte Carlo method was applied to test the statistical significance and robustness of the composite results (Livezey and Chen 1983; Wilks 1995). Monte Carlo simulation was repeated 1,000 times for each composite analysis.

\section{Results}

3.1 Variation of the NASH western ridge and its relationship to the US summer precipitation during the period 1948-2007

In recent decades, the NASH has intensified and moved westward, its western ridge exhibiting enhanced meridional movement on interannual timescales ( $\mathrm{Li}$ et al. 2011). Figure 2 demonstrates the interannual variations of the NASH western ridge relative to its climatological mean location $\left(86^{\circ} \mathrm{W}, 27^{\circ} \mathrm{N}\right)$ in the boreal summer JJA during the 60-year period (1948-2007). Our previous studies suggested that interannual variability of summer precipitation in the SE US intensified during the last three decades (1978-2007) compared to the earlier three decades (1948-1977) (Wang et al. 2010). Thus, the 60 locations of the NASH western ridge are plotted in Fig. 2 using two different shapes to highlight the difference between the two periods. In the first 30-year period, the distribution of western ridges was concentrated in the NE and SE quadrants; whereas in the second 30-year period, about $80 \%$ of ridges were located in the SW and NW quadrants. This indicates a westward extension of the ridge similar to that described in $\mathrm{Li}$ et al. (2011). During the most recent 30 years (1978-2007), 40\% more ridges were located in the NW quadrant. 
Corresponding to the different locations of the NASH's western ridge, the precipitation distribution and associated atmospheric circulation exhibits different patterns. Figure 3 shows the composite results of US summer precipitation based on the four NASH western ridge locations (Fig. 2). The NW ridge pattern corresponds to positive precipitation anomalies over the Pacific, the Northwestern US, and especially over the Great Lakes area (Fig. 3a). Negative anomalies are observed mainly in the SE US (Fig. 3a). The rainfall deficit in the SE US is larger than $0.8 \mathrm{~mm} \mathrm{day}{ }^{-1}$, equivalent to about one standard deviation of summer rainfall in the region (Wang et al. 2010). Such a reduction in summer precipitation would place great stresses on water availability in the SE US during the NW ridge position years. The spatial distribution of precipitation anomalies indicates a North-South oriented dipole pattern (Fig. 3a).

Precipitation anomalies corresponding to the SW ridge cases exhibit the opposite pattern (Fig. 3b). Negative rainfall anomalies are located over the Northern US, whereas positive anomalies prevail over the SE US, except southern Florida. Precipitation anomalies are usually above one standard deviation in Alabama, Georgia, Tennessee, and the western Carolinas. The SE US summer precipitation demonstrates a stronger response to the meridional migration of the NASH western ridge when the ridge extends westward (Fig. 3a, b).

When the western ridge is located east of its climate mean position, mainly during the 1 st 30 year interval, precipitation anomalies over the SE US are not as strong and less uniform (Fig. 3c, d). The precipitation corresponding with the NE ridges is characterized by negative

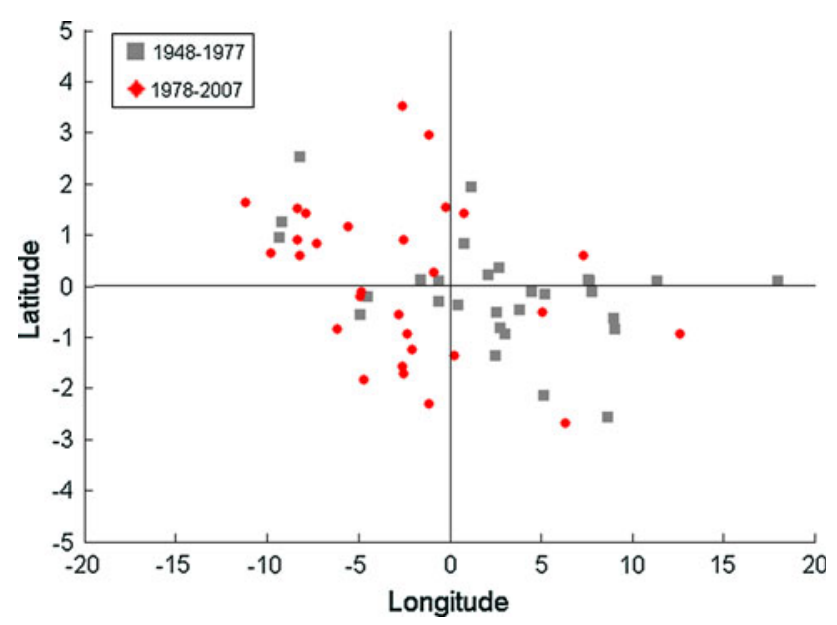

Fig. 2 Spatial distributions of the NASH western ridge relative to its climatological mean position $\left(86^{\circ} \mathrm{W}, 27^{\circ} \mathrm{N}\right)$ during the period 1948-2007. The gray squares denote the western ridge positions during the first 30-year (1948-1977); the red dots during the second 30-year (1978-2007), respectively anomalies over the Northern United States and the Ohio Valley (Fig. 3c). The average precipitation anomaly is less uniform and insignificant in the Southern US. Significant positive anomalies in precipitation are confined to a narrow region extending from the Northeastern US to Texas. Overall, both positive and negative precipitation anomalies are $50 \%$ weaker in the southern states compared with those in the Midwest (Fig. 3c). The precipitation anomalies are weakest when the NASH western ridge is located in the SE quadrant (Fig. 3d). Significant anomalies only occur in the south of Texas (dry), as well as Oklahoma and Arkansas (wet).

Figure 4 shows moisture divergence and vertical motion associated with the four different ridge types. When the ridge is located in the NW quadrant, moisture is transported along the NASH western ridge into Texas and the Midwestern US instead of the SE US (Fig. 4a). This intensified northward transport of moisture is likely associated with the stronger than normal Great Plains low-level jet (GPLLJ). In the NW years, the meridional wind increases by $13 \%$ compared to the climatology (not shown). The intensification of the GPLLJ brings excessive moisture and precipitation into the Great Plains and central US as also suggested by previous studies (Arritt et al. 1997; Mo and Berbery 2004; Ting and Wang 2006; Weaver and Nigam 2008; Weaver et al. 2009; Cook et al. 2011). Concomitantly, downward motion prevails in the SE US, depressing convection in the region (Fig. 4a). Therefore, the large-scale circulation conditions result in anomalous dry conditions over the SE US. In contrast, when the NASH western ridge is located in the SW quadrant, moisture is transported mainly into the SE US and converges in this region (Fig. 4b). The associated upward motion over the SE US further facilitates convection that drives precipitation (Fig. $4 \mathrm{~b}$ ). Similar to the precipitation responses to the eastward ridges (Fig. 3c, d), the moisture fluxes and atmospheric vertical motion are weaker in the SE US when the ridges are located in the NE and SE quadrants (Fig. 4c, d).

Figures 3 and 4 suggest that the position of the NASH western ridge is closely linked to the observed variability in summer precipitation within the SE US by altering moisture transport and vertical motion over the region. When the NASH western ridge is located in the NW and SW quadrants as is primarily the case during the 2nd time period (1978-2007), its impact on SE US precipitation is enhanced compared to the NE and SE ridge locations. This also explains why the variability increased in the 2nd time period: with the ridge moving westward, the north-south fluctuations lead to rainfall variability, whereas when the ridge is in the east, such latitudinal fluctuations fail to significantly affect summer precipitation (see also Li et al. 2011). 
Fig. 3 Composite summer precipitation anomalies (shaded; $\mathrm{mm} \mathrm{day}^{-1}$ ) over the US based on $850 \mathrm{hPa} \mathrm{NASH}$ western ridge positions, a Northwest ridging; b Southwest ridging; c Northeast ridging; and d Southeast ridging. Stippled areas show where precipitation anomaly is statistically significant at the $95 \%$ confidence level

Fig. 4 Composite results of the $500 \mathrm{hPa}$ vertical pressure velocity anomaly (contour, unit: $10^{-2} \mathrm{~Pa} \mathrm{~s}^{-1}$ ), moisture flux (vectors, unit: $\mathrm{Kg} \mathrm{m} \mathrm{s}^{-1}$ ), and moisture divergence anomaly ( shaded, unit: $\mathrm{mm} \mathrm{day}^{-1}$ ) over the US based on $850 \mathrm{hPa}$ NASH western ridge positions: a Northwest ridging; b Southwest ridging; c Northeast ridging; and d Southeast ridging. Only grid points passing $95 \%$ confidence level are plotted (a) Northwest

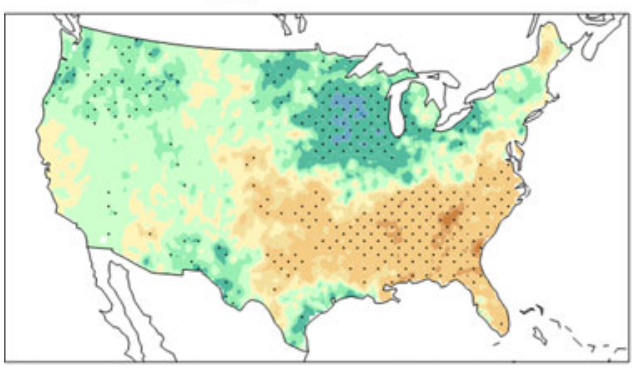

(b) Southwest

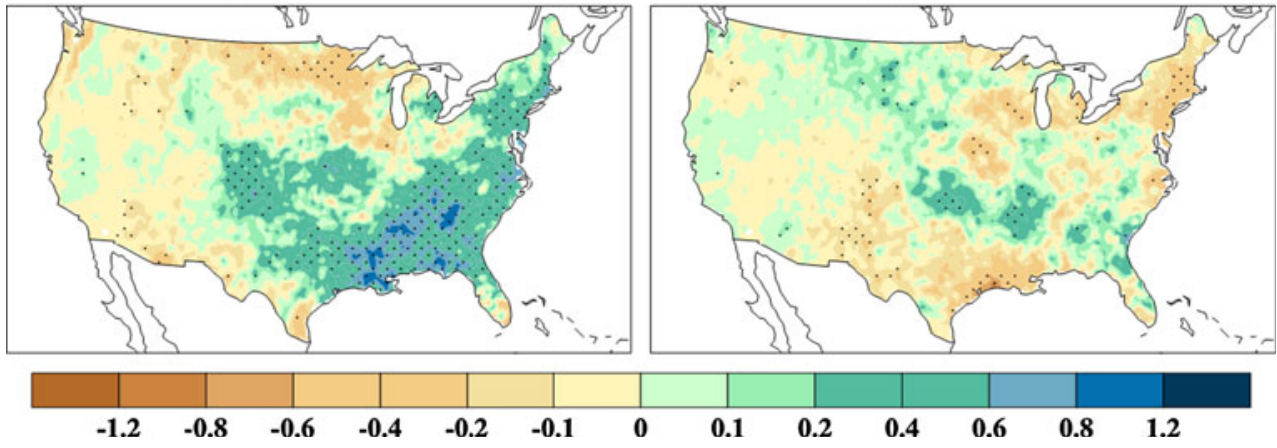

(c) Northeast

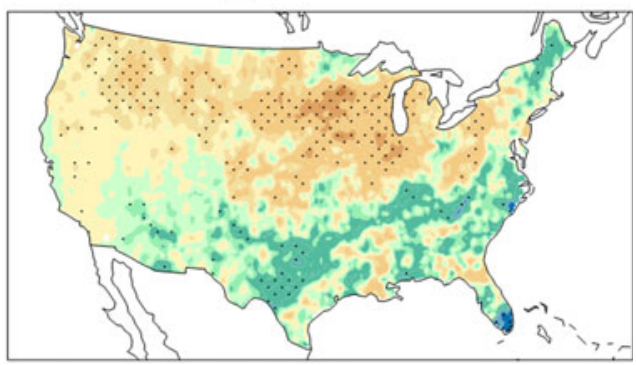

(d) Southeast (a) Northwest

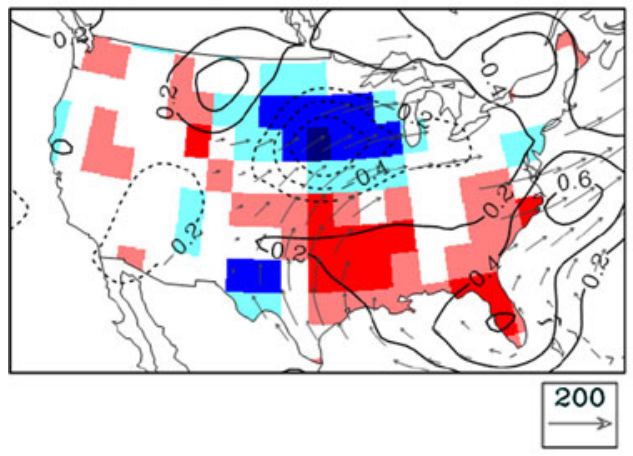

(b) Southwest

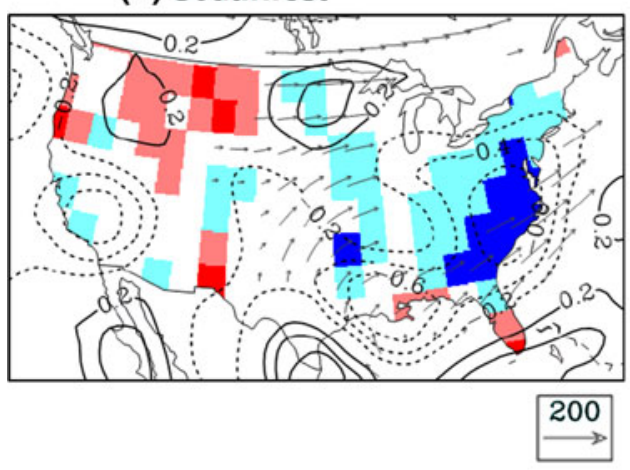

(c) Northeast

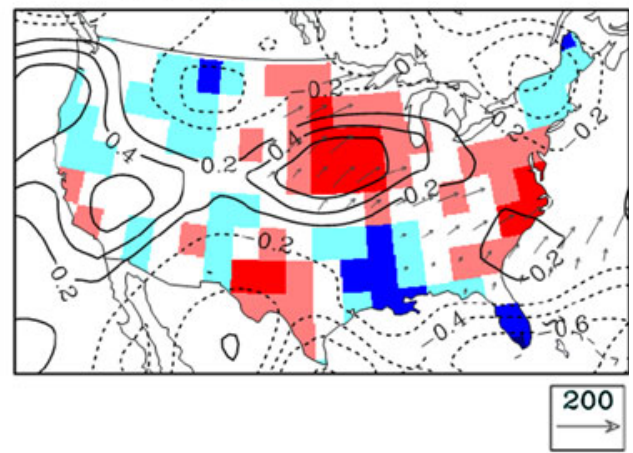

(d) Southeast

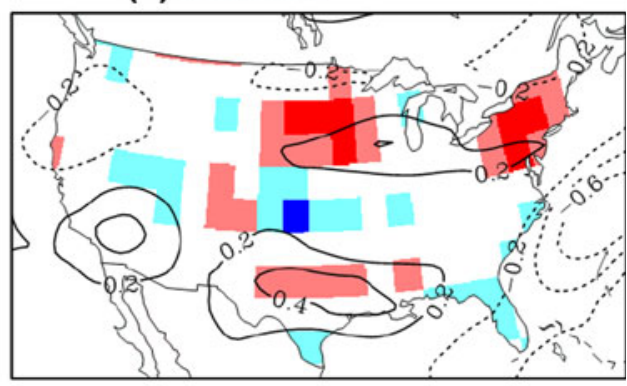

200

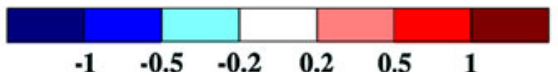


3.2 What controls the movement of the NASH western ridge?

Atmospheric circulation fields were analyzed in order to identify the processes that contribute to the movement of the NASH western ridge. Figure 5 illustrates the composite results of $850 \mathrm{hPa}$ geopotential height and anomalies that correspond to each of the four ridge types. When the NASH western ridge extends westward, positive geopotential height anomalies are observed over the Atlantic Ocean (Fig. 5a, b). In contrast, negative anomalies are observed when the ridge retreats eastward (Fig. 5c, d). Specifically, when the ridge is located in the NW quadrant, the NASH's center is around $35^{\circ} \mathrm{N}, 40^{\circ} \mathrm{W}$. Significant geopotential height anomalies extend from Northern Africa to the SE US along the southern flank of the NASH. The maximum response of positive geopotential height anomalies is over the SE US, no significant signals are observed near the NASH's center (Fig. 5a).

(a) Northwest

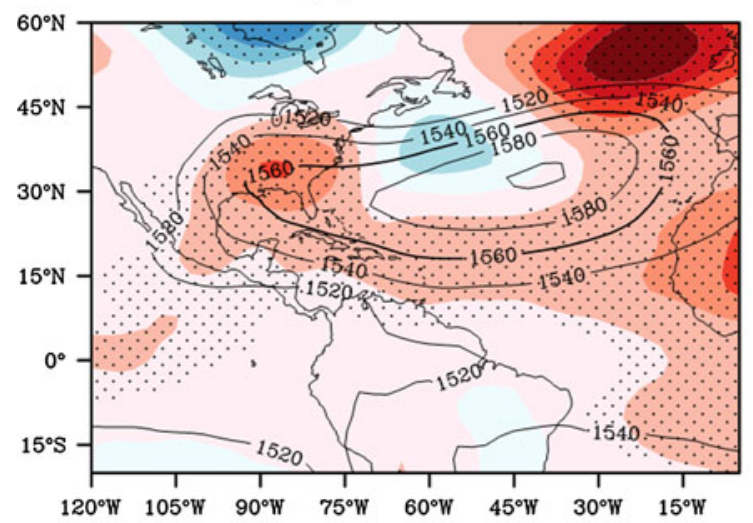

(b) Southwest

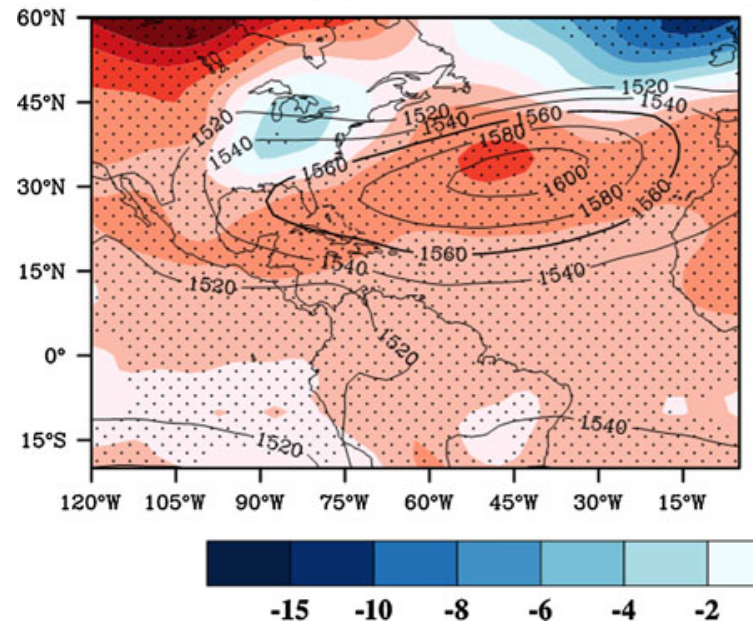

Fig. 5 Composite results of $850 \mathrm{hPa}$ geopotential height (contour, unit: gpm), and geopotential height anomaly (shaded, unit: gpm) based on the NASH western ridge positions: a Northwest ridging;
In summers dominated by SW quadrant positions, the NASH's center is located at $\left(30^{\circ} \mathrm{N} 45^{\circ} \mathrm{W}\right)$, with an increase of intensity by $5 \mathrm{gpm}$ (Fig. $5 \mathrm{~b}$ ). The center of the subtropical high, as represented by the area enclosed by the $1,600-\mathrm{gpm}$ isoline, is the largest among the 4-ridge composites (Fig. 5). Positive geopotential height anomalies are more uniform over the North Atlantic in summers with a SW ridge position than when it is in a NW position (Fig. 5a). The maximum positive anomalies fall close and around the mean location of the NASH center (Fig. 5b). This indicates that SW ridging might be mainly caused by the intensification and expansion of the NASH system.

For both NE and SE ridge types (Fig. 5c, d), the intensities of the NASH center are $\sim 1,590 \mathrm{gpm}$, about $10 \mathrm{gpm}$ weaker than when NW and SW ridge types are present (Fig. 5a, b). This suggests that a weakened NASH leads to an eastward retreat of the NASH western ridge (Fig. 5c, d).

\section{(c) Northeast}

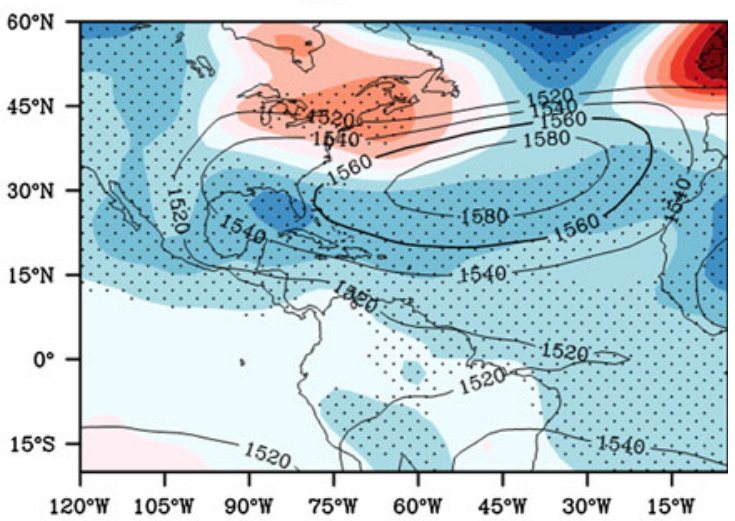

(d) Southeast

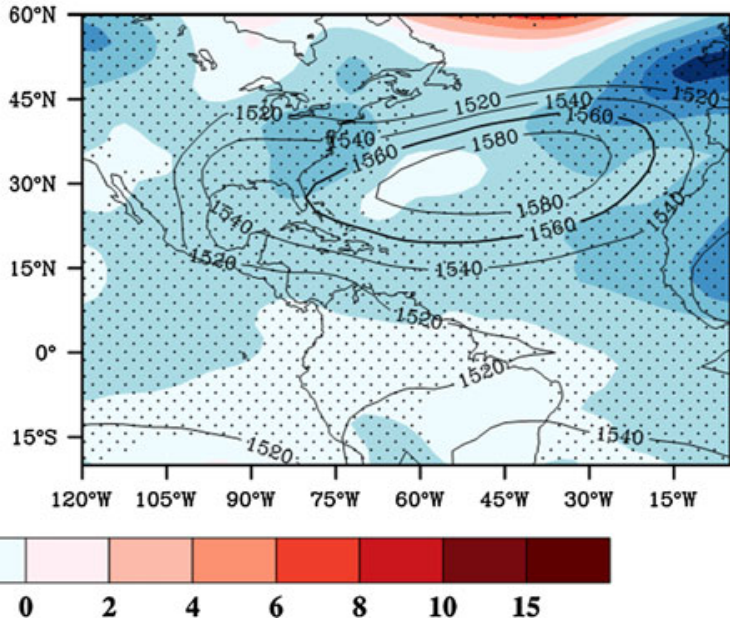

b Southwest ridging; c Northeast ridging; and d Southeast ridging. Stippled areas show where the $850 \mathrm{hPa}$ geopotential height anomaly is statistically significant at the $95 \%$ confidence level 
Overall, an intensified (weakened) NASH is related to the westward extension (eastward retreat) of the NASH western ridge and thus an enhanced (weakened) impact on the SE US summer rainfall. Of the two westward ridges, the SW type is more likely linked with the intensification and expansion of the NASH, whereas the NW type shows no apparent relationship to the NASH center's intensity. Instead, the maximum geopotential height anomalies are located over the SE US, suggesting influences other than the NASH center contribute to NW ridging. Here we are more interested in the two western ridges because of the more important role they play in influencing SE US precipitation. Hereafter, we will focus on the possible mechanism responsible for these SW and NW ridge locations.

\subsubsection{The contribution of the NASH center's intensity to the $S W$ ridging}

The atmospheric circulation in summers with SW ridging is characterized by the intensification and a uniform expansion of the NASH (Fig. 5b). The intensification of the NASH enhances the North Atlantic subtropical circulation (Fig. 6a): the easterly winds south of the NASH ridge are observed to strengthen near the surface and in the lower troposphere (Fig. 6a, b). Augmentation of easterly winds (Fig. 6b), enhances the heat loss from the ocean's surface, mainly in the form of surface evaporation. Such heat loss would lower SST and thus cause negative SSTAs over the tropical Atlantic region (Fig. 6b). Cold SSTs can, in turn, reinforce the anticyclone (Seager et al. 2003; Kushnir et al. 2010).

Because SSTs are lowered due to enhanced surface evaporation, the atmospheric boundary layer is stabilized. This can be seen by an increase of static stability at the lower atmospheric layer in Fig. 6d. In SW ridge years, the static stability increases below $800 \mathrm{hPa}$, indicating that more energy is required to overcome the atmospheric stratification for upward motion and convection to take place. Thus, tropical convective activity tends to be depressed and precipitation decreases.

Using the Global Precipitation Climatology Project (GPCP) data (Huffman et al. 1997), we found that precipitation over the Caribbean is significantly below normal with decreased SST in the SW summers (Fig. 6c). Consequently, condensational heating associated with precipitation would decrease in the middle troposphere. Such reduction in condensational heating would induce a Gilltype atmospheric response (Gill 1980), with an anomalous anticyclone to the northwest of the heating center. Colocated with the southern portion of the NASH western ridge, this anticyclonic circulation facilitates the southwestward extension of the NASH ridge (Kushnir et al. 2010).
To verify that NASH center's intensification favors SW ridging, a linear regression analysis of $850 \mathrm{hPa}$ geopotential height upon the NASH center's intensity was performed (Fig. 6e). Figure 6e shows that when the NASH center's intensity increases by one standard deviation, the NASH tends to expand southwestward and the 1,560-gpm isoline extends by three degrees westward relative to its average climatological position. This is similar to the composite results based on analysis of the SW ridges (Fig. 5b).

\subsubsection{The relationship between the Pacific decadal oscillation and $N W$ ridging}

In contrast to the SW-type ridges, the NASH center's intensity shows no significant deviation from its climatological mean when the NASH western ridge is located in the NW quadrant. The maximum $850 \mathrm{hPa}$ geopotential height anomaly is observed over the SE US (Fig. 5a). Furthermore, the atmospheric circulation associated with the NW ridging demonstrates an equivalent barotropic structure with both lower and upper atmospheric layers dominated by positive geopotential height anomalies, as seen from the vertical profile of the geopotential height anomalies averaged over the SE US $\left(30^{\circ} \mathrm{N}-37.5^{\circ} \mathrm{N}\right)$ in NW-position years (Fig. 7a). Positive anomalies of geopotential height are significant throughout the whole troposphere. The center of the positive geopotential height anomaly in the upper troposphere is located over the Midwest (Fig. 7a), and shifts to the SE US near the surface (Figs. 5a, 7a). The barotropic structure is spatially uniform along all latitudes in the SE US (not shown).

The barotropic structure shown in Fig. 7a indicates that the local thermal forcing, especially the condensational heating associated with precipitation anomalies, is not a forcing factor for the NW ridging because local diabatic heating in the summertime subtropics tends to cause a baroclinic response of the atmospheric circulation ( $\mathrm{Wu}$ and Liu 2003; Liu et al. 2004; Wu et al. 2009). Thus, the NW ridging is more likely caused by dynamic forcings (Fig. 7a).

Figure $7 \mathrm{~b}$ shows the composite SSTAs when the NASH western ridges are located in the NW quadrant. As seen from Fig. 7b, significant SSTAs are mainly located in the North Pacific. In contrast, the North Atlantic SSTAs are relatively weak and insignificant (Fig. 7b). Figure 7b indicates that the NW ridging is more likely associated with Pacific rather than with Atlantic SSTAs. In the North Pacific, positive SSTAs are observed in the tropics and negative SSTAs in the mid-latitudes. Such a pattern is similar to the SSTA associated with the Pacific decadal oscillation (PDO) (Mantua et al. 1997; Zhang et al. 1997; Mantua and Hare 2002). Although SSTA during the NW years exhibit positive anomalies over the tropical eastern Pacific, their magnitudes are too weak to be statistically 
(a)

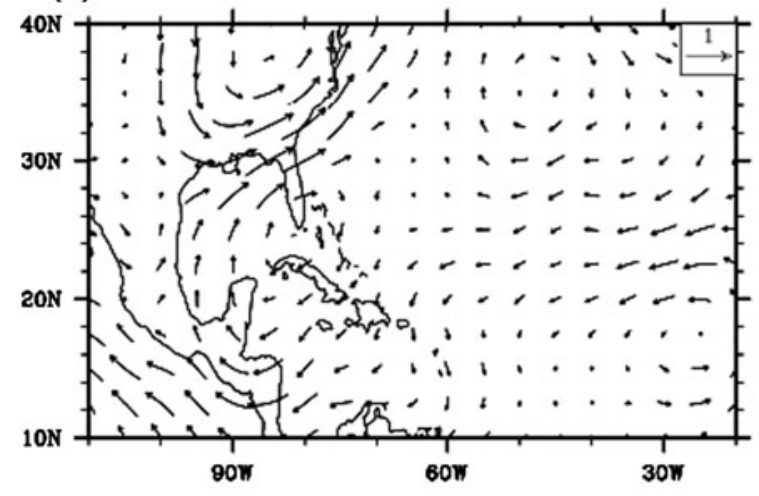

(c)

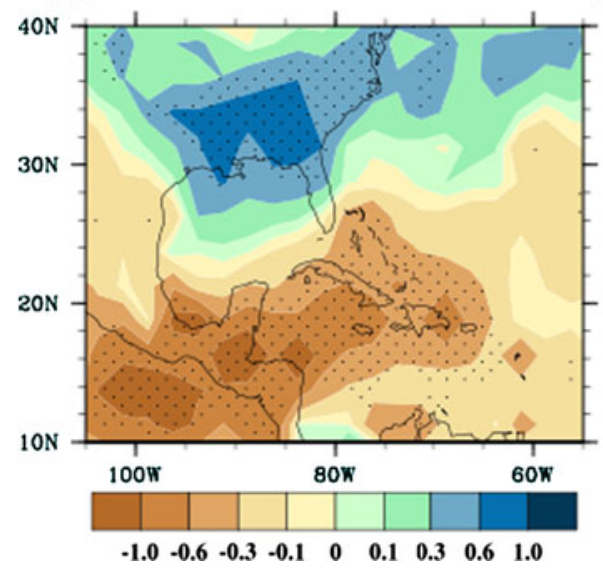

(d)

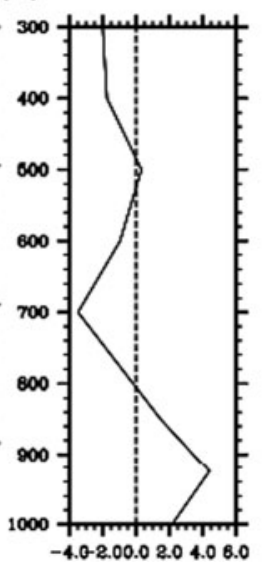

(b)

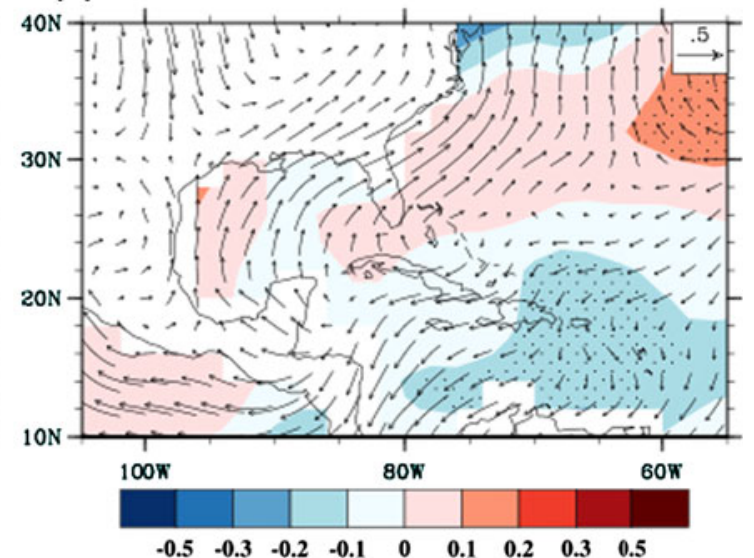

(e)
Fig. 6 Composite results of a $850 \mathrm{hPa}$ wind anomaly (vector, unit: $\mathrm{m} \mathrm{s}^{-1}$ ); b Surface wind anomaly (vector, unit: $\mathrm{m} \mathrm{s}^{-1}$ ) and SSTA (shaded, unit: K), stippled areas show where SSTA is statistically significant at the 95\% level; c Precipitation anomalies measured by GPCP data (unit: $\mathrm{mm} \mathrm{day}{ }^{-1}$ ), stippled areas are where precipitation anomalies are statistically significant at $95 \%$ confidence level;

significant. We conclude that the SST anomalies are mainly forced by the PDO instead of the ENSO.

To further verify the possible influence of the PDO on NW ridging, Fig. 7c lists the times series of the PDO index and NW years during the years 1948-2007. The PDO index is negative during 1947-1976 and becomes positive during 1977-2007, with a regime shift in 1976/1977 (Mantua and Hare 2002, Fig. 7c). In the 60-year interval, 13 NW summers occur within a positive and 6 summers within a negative PDO phase. The fact that the number of NW-position years during the positive PDO phase is more than double the number during the negative PDO phase, suggests that the decadal variation of Pacific SSTA impacts the NASH western ridge position by modulating the stationary wave source over the eastern Pacific/US western coast (see Fig. 7d, e).

Figure $7 \mathrm{~d}$ shows composite results of $200 \mathrm{hPa}$ geopotential height and Plumb flux anomalies during the NW years. The positive anomalies in geopotential height over d Vertical profile of Brunt-Vaisala frequency anomaly (unit: $10^{-6}$ $\left.\mathrm{s}^{-2}\right)$ averaged over tropical North Atlantic oceans $\left(80^{\circ} \mathrm{W}-60^{\circ} \mathrm{W}\right.$, $\left.12.5^{\circ} \mathrm{N}-20^{\circ} \mathrm{N}\right)$ in the SW summers. e 1,560 -isoline of $850 \mathrm{hPa}$ geopotential height regressed upon NASH center's intensity: red (blue) contour marks the regression result when NASH center's intensity increased (decreased) by one standard deviation

North America appear to be part of the stationary wave train in the Northern hemisphere. Stationary wave flux diverges from the midlatitudes of the eastern Pacific/US western coast and moves towards the positive geopotential height anomaly center over the eastern US. This indicates that the observed stationary wave activity over the US is forced from the eastern Pacific/US western coastal region. The composite Plumb flux anomaly at $200 \mathrm{hPa}$, based on the PDO positive index during the years 1948-2007, is illustrated in Fig. 7e. The pattern of the Plumb flux in the NW years (Fig. 7d) resembles that of the Plumb flux composite of the positive PDO phase (Fig. 7e), suggesting that NW-type ridges are favored to occur in the warm phase of the PDO.

The quasi-barotropic character of stationary wave activity of the eastern Pacific/western US coastal region explains the observed vertical structure of the geopotential height anomalies in Fig. 7a and the anomalous geopotential 


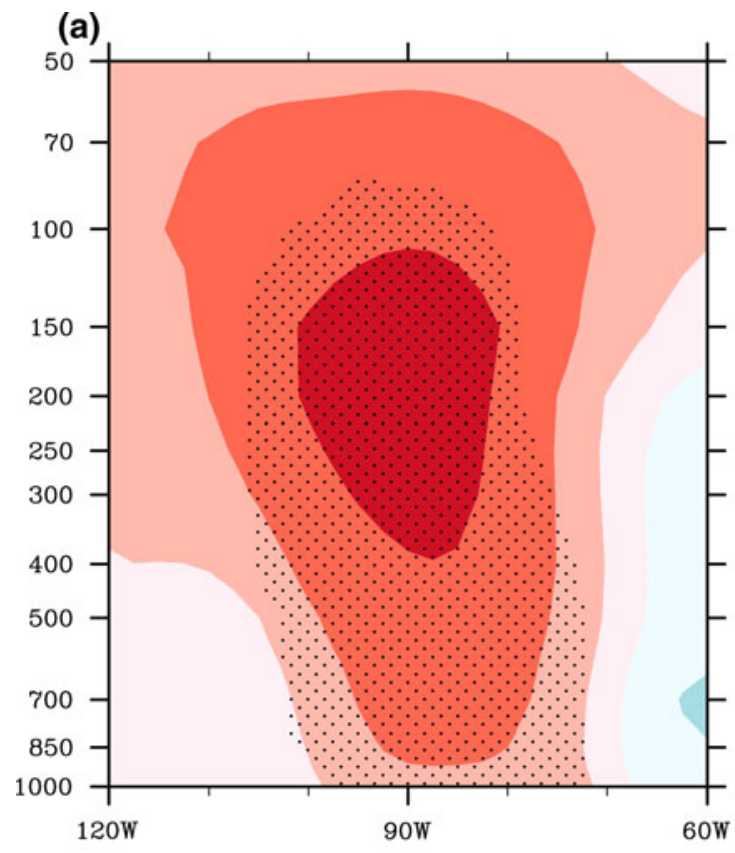

(d)

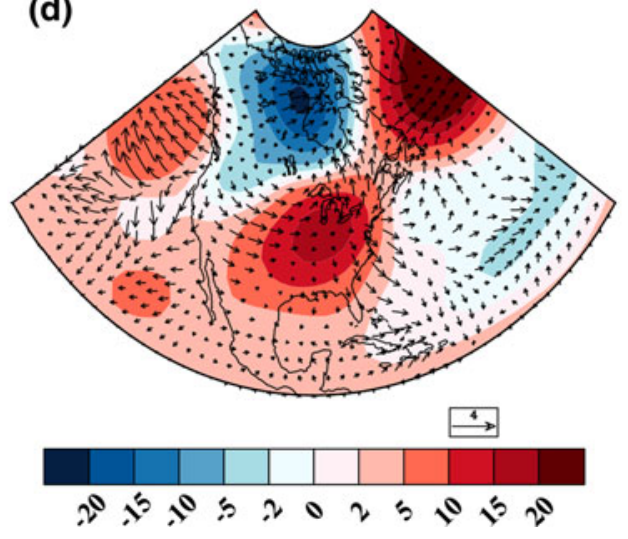

Fig. 7 Composite results of a Vertical profile of geopotential height (shaded, unit: gpm) along the $30^{\circ} \mathrm{N}-35^{\circ} \mathrm{N}$ latitudinal band; and b SSTA (shaded, unit: K) in the NW summers. c Time series of the PDO index during 1948-2007 where the red bar denotes NW summers. d Composite $200 \mathrm{hPa}$ geopotential height anomaly (shaded,

height at $850 \mathrm{hPa}$ level over the SE US (Fig. 5a). The latter favors the northwestward extension of the NASH western ridge.

\section{Discussions}

The enhanced summer rainfall variability in the SE US was found to be related to variations in the NASH during recent decades. During this period (1978-2007), the NASH intensified, moved westward, and has been characterized by enhanced meridional movements of its western ridge $(\mathrm{Li}$ et al. 2011). Our analysis based on the four different ridge types further supports that the summer rainfall variability in the SE US was directly linked to variations in the location

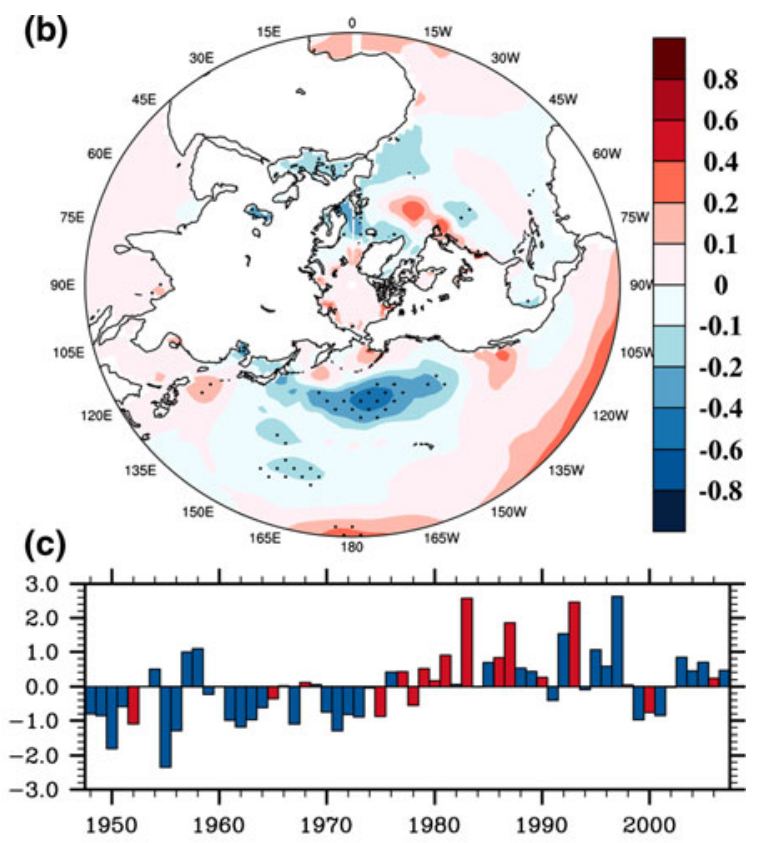

(e)

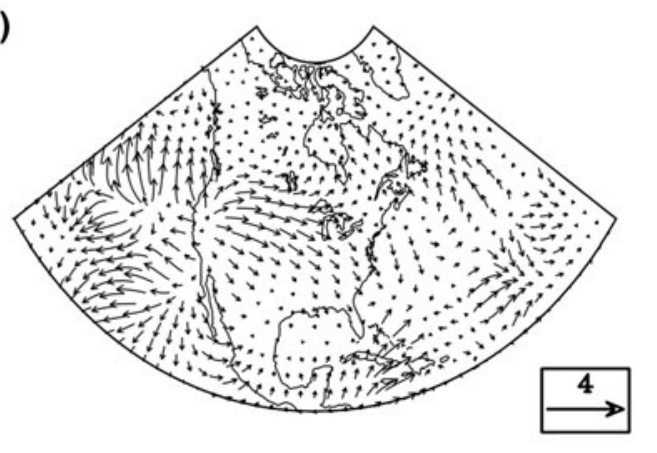

unit: gpm) and Plumb flux anomaly (vector, unit: $\mathrm{m}^{2} \mathrm{~s}^{-2}$ ), and e Composite plumb flux anomalies (vector; $\mathrm{m}^{2} \mathrm{~s}^{-2}$ ) for positive PDO index. Stippling in $\mathbf{a}$ and $\mathbf{b}$ denotes areas where geopotential height and SSTA are statistically significant at the $95 \%$ confidence level. The color scale in a is the same as that in $\mathbf{d}$

and intensity of the NASH, especially in the last three decades when the NASH moved closer to the continental US. Thus, analysis of the variations in the NASH western ridge can provide insights for future prediction of summer precipitation over the SE US.

Figure 8 displays the distribution of the four ridge types $^{3}$ in the preindustrial (PICNTRL, 50-year), in the 20th (20C3M, 1950-1999) and the twenty-first century simulations (SRESA1B, 2050-2099) obtained from all the 23

\footnotetext{
${ }^{3}$ To avoid the possible spread of the western ridge among the CMIP3 models and to make results comparable, we used the climatological contour straddling the longitude of $86^{\circ} \mathrm{W}$ to represent the western edge of the NASH for each model under scenario 20C3M. This longitude is derived according to observed climatological NASH location based on the NCEP reanalysis data (Li et al. 2011).
} 
coupled climate models of the phase 3 of the Coupled Model Intercomparison Project (CMIP3) (Meehl et al. 2007). When $\mathrm{CO}_{2}$ concentration is kept at its pre-industry level (PICNTRL), the NE- and SE-type ridges were more frequent (Fig. 8). In the twentieth century (20C3M), NEtype ridge decrease by $71 \%, \mathrm{SW}$ - and $\mathrm{NW}$-type ridges increase by 67 and 59\%, respectively. The SW-type ridge shows a continuous increase and becomes the highest occurrence rate in the twenty-first century (SRESA1B). Li et al. (2011) found that the significant intensification of the NASH during the past 60 years is associated and consistent with global warming. Our results further indicated that the occurrence frequency of SW summer increases more consistently because the SW-type ridging is mainly associated with a strengthening of the NASH center's intensity.

On average, the occurrence rate of NW-type ridge slightly decrease in the twenty-first century (SRESA1B) compared to that of the twentieth century (20C3M), but the change of the NW-ridge frequency is not significant $\left(\chi^{2}\right.$ test $)$. Compared to the sharp continuous increase of SW-type ridge in the twenty-first century (SRESA1B), the NW-type ridge is less affected by the increase of greenhouse gases (GHGs). This is most likely because the NW-type ridge is primarily influenced by the PDO, which is projected to undergo no significant changes in the future (Furtado et al. 2011). Using the NCEP/NCAR reanalysis, we found that the NW ridging does exhibit a decadal variation during 1948-2007 (not shown). The highest occurrence rate of NW-type years was between years 1978-1992. Following this, the rate decreased alongside a decrease in the PDO index after 1999, suggesting a linkage between the NW ridging and changes in the PDO.

From these results we conclude that the intensified interannual variability in the SE US summertime

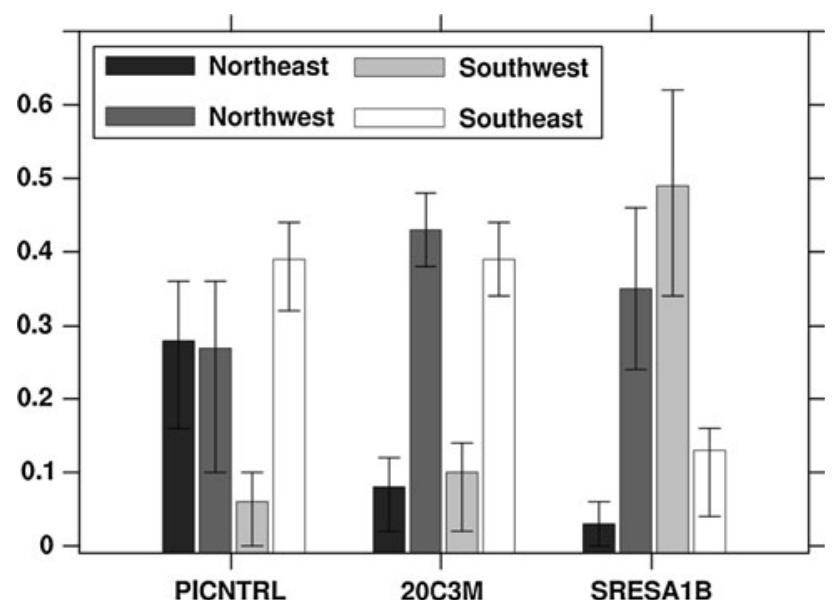

Fig. 8 Occurrence rate of 4 ridge types as simulated by 23 CMIP3 models under PICNTRL, 20C3M and SRESA1B scenarios. The bottom and top of each error bar shows the 25th and 75th percentile value among 23 CMIP models precipitation during recent decades might be a combined effect of decadal variation and the anthropogenic climate change trend. The PDO and global warming act on opposite ends for the SE US summer precipitation. In the future, with further increases of GHGs, we expect an intensified NASH ( $\mathrm{Li}$ et al. 2011), more SW ridging, and abnormally wet summers over the SE US. Meanwhile, because the occurrence of NW-type is mainly linked to the PDO index, a positive value will result in NW-ridging, which in turn will bring drier summer to the SE US. Thus, the SE US may experience wetter summers and, occasionally, drought conditions in the twenty-first century, depending on the strength of the PDO positive phase and the NASH intensity, which needs further quantification in the future.

\section{Conclusion}

Using NCEP/NCAR reanalysis data, US. Unified Precipitation data, and the real-time US. Daily Precipitation Analysis, variations in the NASH western ridge and its potential influence on the SE US summer precipitation were studied. Our results confirm that the western ridge of the NASH has moved westward in the last three decades. By modulating moisture transport (zonal movement) and vertical motion (meridional movement), these changes in the NASH have impacted SE US rainfall patterns.

Our composite results, based on a two-dimensional displacement of the NASH western ridge relative to its climatological mean position, indicate that the westward relocation of the NASH western ridge causes more uniform and intensified precipitation anomalies over the SE US. When the NASH western ridge is located in the SW (NW) quadrant, the SE US experiences severe pluvial conditions (drought). In contrast, the precipitation anomalies weaken when the NASH western ridge is located relatively eastward.

These ridge patterns are connected with conspicuously different atmospheric circulation patterns controlled by distinct physical mechanisms. The SW type is likely the results of the intensification and systematic expansion of the NASH system. This enhancement of the North Atlantic subtropical circulation is viewed to increase surface winds and evaporation resulting in decreased SSTs over the Gulf of Mexico. The cooling of the surface ocean would depress tropical convection, resulting in decreased condensational heating. Accompanying this diabatic-heating anomaly, the atmospheric circulation shows a typical Gill-type response with an anticyclone developing northwest of the diabatic heating anomalies. Such circulation would favor the southwestward extension of the NASH western ridge. Thus, our results suggest that the SW ridge type involves the interaction of the NASH system with the tropical ocean, which may stem from the NASH center intensification. 
The atmospheric circulation in the NW years exhibits a weaker link to the NASH center change. Instead, the maximum increase of geopotential height is over the SE US with an equivalent-barotropic pattern. This suggests that influence from local diabatic heating is less important. Analysis of Plumb flux indicates that the anomalous geopotential height over the SE US might be dynamically forced by a stationary wave train emanating from the western coast of the US, a situation that is associated with the positive phase of the PDO.

Our analysis of the NASH western ridge patterns and the SE US summer precipitation suggests that enhanced precipitation variability in recent decades is a combined result of the PDO and NASH center intensifications that are associated with global warming ( $\mathrm{Li}$ et al. 2011). In the future, as warming continues, the frequency of SW-type ridge positions are predicted to increase significantly, resulting in increasingly wet summers in the SE US. However, this wetting trend will occasionally be opposed by drying summers when NW-ridge types occur during positive PDO phases.

Acknowledgments We thank the international modeling groups for providing their data for analysis, the Program for Climate Model Diagnosis and Intercomparison (PCMDI) for collecting and archiving the model data, the JSC/CLIVAR Working Group on Coupled Modeling (WGCM) and their Coupled Model Intercomparison Project (CMIP) and Climate Simulation Panel for organizing the model data analysis activity, and the IPCC WG1 TSU for technical support. The IPCC Data Archive at Lawrence Livermore National Laboratory is supported by the Office of Science, US Department of Energy. We thank Drs. M. Susan Lozier, Ming Cai, Amy Clement, Paul A. Baker, Ana Barros, Robert E. Dickinson, and Jiansheng Ye and two anonymous reviewers for their insightful comments, and Dr. Alex Glass and Ms. Diane Bryson for editorial assistance. This work is supported by startup funds from Duke University and the Nicholas School Office of the Dean. Y. Kushnir was supported by NOAA Grant NA10OAR4310137.

\section{References}

Arritt RW, Rink TD, Segal M, Todey DP, Clark CA, Mitchell MJ, Labas KM (1997) The Great Plains low-level jet during the warm season of 1993. Mon Weather Rev 125:2176-2192

Barlow M, Nigam S, Berbery EH (2001) ENSO, Pacific decadal variability, and US summertime precipitation, drought, and stream flow. J Clim 14:2105-2128

Black RX (1997) Deducing anomalous wave source regions during the life cycles of persistent flow anomalies. J Atmos Sci 54:895-907

Chan SC, Misra V (2010) A diagnosis of the 1979-2005 extreme rainfall events in the Southeast US with isentropic moisture tracing. Mon Weather Rev 138:1172-1185

Chen P, Newman M (1998) Rossby wave propagation and the rapid development of upper-level anomalous anticyclones during the 1988 US drought. J Clim 11:2491-2504

Cook BI, Seager R, Miller RL (2011) Atmospheric circulation anomalies during two persistent North American droughts: 1932-1939 and 1948-1957. Clim Dyn 36:2339-2355
Curtis S (2008) The Atlantic multidecadal oscillation and extreme daily precipitation over the US and Mexico during the hurricane season. Clim Dyn 30:343-351

Davis RE, Hayden BP, Gay DA, Phillips WL, Jones GV (1997) The North Atlantic subtropical anticyclone. J Clim 10:728-744

Diem J (2006) Synoptic-scale controls of summer precipitation in the Southeastern United States. J Clim 19:613-621

Franzke C, Fraedrich K, Lunkeit F (2001) Teleconnections and lowfrequency variability in idealized experiments with two storm tracks. Quart J Roy Meteor Soc 127:1321-1339

Furtado JC, Lorenzo ED, Schneider N, Bond NA (2011) North Pacific decadal variability and climate change in the IPCC AR4 models. J Clim 24:3049-3067

Gamble DW, Parnell DB, Curtis S (2008) Spatial variability of the Caribbean mid-summer drought and relation to north Atlantic high circulation. Int J Climatol 28:343-350

Gill AE (1980) Some simple solutions for the heat induced tropical circulation. Quart J Roy Meteor Soc 106:447-462

Gotvald AJ, McCallum BE (2010) Epic flooding in Georgia, 2009: US Geological survey fact sheet 2010-3107, 2p

Henderson KG, Vega AJ (1996) Regional precipitation variability in the southeastern United States. Phys Geogr 17:93-112

Higgins RW, Shi W, Yarosh E, Joyce R (2000) Improved United States precipitation quality control system and analysis. NCEP/ Climate Prediction Center ATLAS No. 7. Camp Springs, MD, $40 \mathrm{pp}$

Honda M, Kushnir Y, Nakamura H, Yamane S, Zebiak SE (2005) Formation, mechanisms, and predictability of the AleutianIcelandic low seesaw in ensemble AGCM simulations. J Clim 25:1423-1434

Hu Q, Feng S, Oglesby RJ (2011) Variations in North American summer precipitation driven by the Atlantic multidecadal oscillation. J Clim (in press). doi:10.1175/2011JCLI4060.1

Huffman GJ et al (1997) The global precipitation climatology project (GPCP) combined precipitation dataset. Bull Am Meteorol Soc 78:5-20

Kalnay E et al (1996) The NCEP-NCAR 40-year reanalysis project. Bull Am Meteorol Soc 77:437-471

Katz RW, Parlange MB, Tebaldi C (2003) Stochastic modeling of the effects of large-scale circulation on daily weather in the southeastern US. Clim Change 60:189-216

Knight DB, Davis RE (2009) Contribution of tropical cyclones to extreme rainfall events in the southeastern United States. J Geophys Res Atmos 114:D23102

Kushnir Y, Seager R, Ting M, Naik N, Nakamura J (2010) Mechanisms of tropical Atlantic SST influence on North American precipitation variability. J Clim 23:5610-5628

Li W, Li L, Fu R, Deng Y, Wang H (2011) Changes to the North Atlantic subtropical high and its role in the intensification of summer rainfall variability in the Southeastern United States. J Clim 24:1499-1506

Liu Y, Wu G (2004) Progress in the study on the formation of the summertime subtropical anticyclone. Adv Atmos Sci 21:322-342

Liu Y, Wu G, Ren R (2004) Relationship between the subtropical anticyclone and diabatic heating. J Clim 17:682-698

Livezey RE, Chen WY (1983) Statistical field significance and its determination by Monte Carlo techniques. Mon Weather Rev 111:46-59

Mantua NJ, Hare SR (2002) The Pacific decadal oscillation. J Oceanogr 58:35-44

Mantua NJ, Hare SR, Zhang Y, Wallace JM, Francis RC (1997) A Pacific interdecadal climate oscillation with impact on salmon production. Bull Am Meteorol Soc 78:1069-1079

Manuel J (2008) Drought in the southeast: lessons for water management. Environ Health Perspect 116:A168-A171 
Meehl GA et al (2007) The WCRP CMIP3 multi-model dataset: a new era in climate change research. Bull Am Meteorol Soc 88:1383-1394

Mo KC, Berbery EH (2004) Low-level jets and the summer precipitation regimes over North America. J Geophys Res Atmos 109:D06117

Mo KC, Schemm JE (2008) Relationship between ENSO and drought over the Southeastern United States. Geophys Res Lett 35:L15701

Nigam S, Chan SC (2009) On the summertime strengthening of the Northern hemisphere Pacific sea level pressure anticyclone. J Clim 22:1174-1192

Plumb RA (1985) On the three-dimensional propagation of stationary waves. J Atmos Sci 42:217-229

Seager R, Murtugudde R, Naik N, Clement A, Gordon N, Miller J (2003) Air-sea interaction and the seasonal cycle of the subtropical anticyclones. J Clim 16:1948-1966

Seager R, Tzanova A, Nakamura J (2009) Drought in the Southeastern United States: causes, variability over the last millennium and the potential for future hydroclimate change. J Clim 22:5021-5045

Smith TM, Reynolds RW, Peterson TC, Lawrimore J (2008) Improvements to NOAA's historical merged land-ocean surface temperature analysis (1880-2006). J Clim 21:2283-2296

Stahle WD, Cleaveland MK (1992) Reconstruction and analysis of spring rainfall over the Southeastern US for the past 1000 years. Bull Am Meteorol Soc 73:1947-1961
Ting M, Wang H (2006) The role of the North American topography on the maintenance of the Great Plains summer low-level jet. J Atmos Sci 63:1056-1068

Wang H, Fu R, Kumar A, Li W (2010) Intensification of summer rainfall variability in the Southeastern United States during recent decades. J Hydrometeorol 11:1007-1018

Weaver SJ, Nigam S (2008) Variability of the Great Plains low-level jet: large-scale circulation context and hydroclimate impacts. J Clim 21:1532-1551

Weaver SJ, Schubert S, Wang H (2009) Warm season variations in the low-level circulation and precipitation over the central United States in observations, AMIP simulations, and idealized SST experiment. J Clim 22:5401-5420

Wilks DS (1995) Statistical methods in the atmospheric sciences. Academic Press, New York

Wu G, Liu Y (2003) Summertime quadruplet heating pattern in the subtropics and the associated atmospheric circulation. Geophys Res Lett 30:1201

Wu G, Liu Y, Zhu X, Li W, Ren R, Duan A, Liang X (2009) Multiscale forcing and the formation of subtropical desert and monsoon. Ann Geophys-Ger 27:3631-3644

Zhang Y, Wallace JM, Battisti DS (1997) ENSO-like interdecadal variability: 1900-1993. J Clim 10:1004-1020 